\title{
Assessing the invasive potential of the Mediterranean fruit fly in California and Italy
}

\author{
Andrew Paul Gutierrez $\cdot$ Luigi Ponti
}

Received: 2 February 2010/Accepted: 13 January 2011 / Published online: 29 January 2011

(C) The Author(s) 2011. This article is published with open access at Springerlink.com

\begin{abstract}
The polyphagous tropical Mediterranean fruit fly (Ceratitis capitata Weid. (medfly)) was detected in California in 1975, and a large-scale detection/eradication campaign was begun in the absence of sound knowledge of the fly's potential invasiveness and geographic distribution. Persistent measurable populations of the fly have not been found in California, but a scientific explanation for this has not developed. A physiologically based demographic system model (CASAS) was developed to examine the effects of temperature on medfly's potential distribution across the ecological zones of Arizona-California (AZ-CA), and in Italy where the fly is established. The system model simulates the
\end{abstract}

A. P. Gutierrez · L. Ponti

Center for the Analysis of Sustainable Agricultural Systems (CASAS Global), 37 Arlington Ave.,

Kensington, CA 94707, USA

A. P. Gutierrez ( $\square)$

Division of Ecosystem Science, Department of Environmental Science, Policy \& Management, University of California, Berkeley, CA 94720, USA e-mail: casas.global@berkeley.edu

URL: http://cnr.berkeley.edu/casas

L. Ponti

Laboratorio Gestione Sostenibile degli Agro-Ecosistemi (UTAGRI-ECO), Agenzia nazionale per le nuove tecnologie, l'energia e lo sviluppo economico sostenibile (ENEA), Centro Ricerche Casaccia, Via Anguillarese 301, 00123 Rome, Italy daily age-mass structured dynamics of a tree host composed of sub-unit populations of leaves, stem, roots and fruit, as well as the age-structured dynamics of medfly life stages. Total pupae tree ${ }^{-1}$ year $^{-1}$ was used as the metric of favorability for medfly at 151 locations in AZ-CA during 1995-2006, and at 84 locations in Italy during 1999-2005. The results were mapped using GRASS GIS. AZ and the southern desert areas of CA are unfavorable for medfly because of high summer temperatures, while much of CA, including many frost-free areas, is too cold. Only the area of south coastal CA (San Diego, Orange and Los Angeles Counties) is potentially favorable for medfly, but in the absence of measurable populations, we cannot say whether it is established there. The majority of medfly discoveries over the past 35 years have occurred in south coastal CA, but discoveries also occurred in Santa Clara County in northern CA, mostly during 1975 and 1980-1981. Santa Clara County, just south of San Francisco Bay, is generally marginal for medfly, but favorability increased approximately $10 \%$ during the period 1979-1981. Medfly has been established in Italy for decades, and our model predicts its wide distribution in the southern and western regions of the country. The fly is restricted in northern areas and at higher elevations of Italy by winter temperatures. Temperature is expected to increase in CA and the Mediterranean Basin. We used two scenarios consisting of increasing observed daily temperatures +2 and $+3^{\circ} \mathrm{C}$ to examine the effects on the potential 
distribution of the fly in CA and Italy. Increasing temperatures expand the favorable range for medfly northward along the coast of CA, but decrease it in the southern reaches of current favorability. A similar but greater increase in geographic range is predicted for Italy. We examine critically some ongoing eradication programs in CA, and question the scientific basis for them. We also review some climate matching approaches used to assess the potential geographic distribution of invasive species.

Keywords Invasive species · Medfly - Eradication · Physiologically-based demographic models · GIS . Population ecology

\section{Introduction}

Invasive species cause estimated annual losses in the USA in excess of $\$ 137$ million (Pimentel et al. 2000). An important invasive species is the polyphagous tropical Mediterranean fruit fly, Ceratitis capitata Weid. (medfly) (Christenson and Foote 1960). Medfly is of East African origins (Balachowski 1950), and is established throughout sub-Saharan Africa, parts of the Mediterranean Basin, areas of South and Central America, Hawaii, Western Australia and elsewhere (see Sutherst et al. 2007; Malacrida et al. 2007). The fly was first detected in California (CA) in 1975 (Carey 1991, 1996a), and an intensive insecticide spraying program was begun to eradicate it. Medfly was not detected again until 1980 (Myers et al. 2000) when an intensive detection and eradication program based on protein bait and Malathion sprays was begun. A sterile male release program was initiated in 1994. As of 2002, more than \$265 million have been spent to eradicate medfly in CA (CDFA 2003), but low numbers of discoveries continue to be made (e.g., Solano County in 2007, and San Diego County in 2008; CDFA 2008).

Carey (1996a) posits that incipient low medfly populations exist in CA, and if correct, the obvious question is why hasn't it spread and increased to pest status as it did in Italy? Is this due to the ongoing eradication efforts, or is climate in CA and Arizona (AZ) mostly outside of its climatic envelope? We can address only the later half of this question.

\section{Estimating the geographic distribution of invasive species}

In the short run, weather and trophic interactions determine local dynamics and phenology of poikilotherms (e.g. Wellington et al. 1999), and in the long run, climate defines their geographic distribution (Andrewartha and Birch 1954; Brown et al. 1996; Walther, 2002; Gaston 2003). A variety of climate matching models have been used to assess the climate envelope of species, and their potential geographic distribution (Coetzee et al. 2009; Sutherst and Bourne 2009). The most widely used methods fall under the ambit of ecological niche models (ENMs). These methods include statistical models (e.g., genetic algorithm for rule-set prediction (GARP), principal components analysis (PCA); see Estrada-Peña 2008; Mitikka et al. 2008), maximum entropy applications based on artificial intelligence concepts (Phillips et al. 2006), and physiological index models (e.g., Fitzpatrick and Nix 1968; Gutierrez et al. 1974; Sutherst and Maywald 1985).

In this paper, we develop a fine-scale, temperaturedriven, distributed-maturation-time, physiologicallybased demographic system model for medfly, and a drought resistant fruit tree host. We use the model to predict the fly's potential distribution and relative abundance in AZ-CA and Italy (CASAS models) under current temperature conditions, and with hypothetical climate warming. We attempt to compare qualitatively our results for AZ-CA and Italy to the coarse-grain global-analysis of Vera et al. (2002) and De Meyer et al. (2008). We also review some ongoing eradication efforts in CA, and assess the use of ENMs for estimating the distribution and invasiveness of pest species.

\section{Methods}

The model

A system model for drought-tolerant olive and the olive fly was used as a template for our fruit treemedfly system (see full details in Gutierrez et al. 2008a, b, 2009). Briefly, the system consists of ten $\{n=1, \ldots, 10\}$ linked functional age-structured population models that may be in units of numbers, mass and/or both. The tree model consists of sub-models 
for the mass of leaves $\{n=1\}$, stem plus shoots $\{n=2\}$ and root $\{3\}$, and the mass and number of healthy $\{4,5\}$ and medfly infested $\{6,7\}$ fruit. The models for medfly consist of age-structured submodels for eggs, larvae and pupae in infested fruit $\{8\}$, and of reproductive and quiescent adults $\{9,10\}$. The underpinning modeling concepts (Gutierrez and Baumgärtner 1984; Gutierrez 1992), model (Gutierrez et al. 2009), and mathematics (DiCola et al. 1999) are outlined in the appendix.

Water and nutrients are assumed non-limiting for the tree, and hence only daily maximum and minimum temperatures, and solar radiation to estimate the photosynthetic rate, are required as inputs. Max-min temperatures are the inputs for the medfly model. Temperature inside fruit in the tree canopy may be $5 \%$ lower or higher than air temperature (Sivinski et al. 2007), but we assume air temperature in the model. Literature data on factors affecting the fly's vital rates are used to parameterize the fly sub-models (see below).

\section{Biology of hosts and medfly}

In the tropics, the host free period may be very short due to overlapping host phenology (e.g., coffee, citrus, guava; Fig. 1a), and this favors the persistence

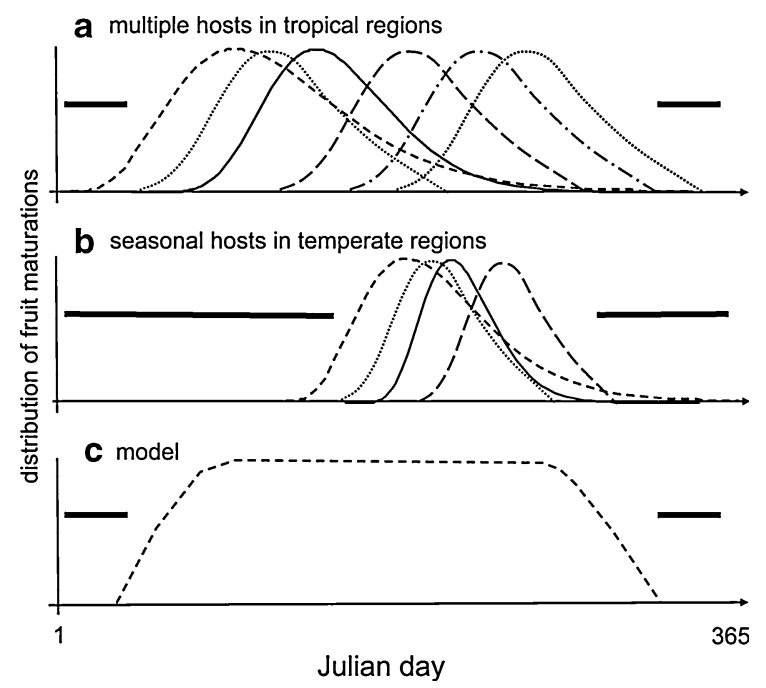

Fig. 1 The stylized phenology of medfly hosts: a tropical areas with multiple hosts, b temperate areas with multiple hosts, and c the generalized fruit phenology used in the analysis. The heavy lines in the figure represent host-free periods of medfly populations. In contrast, host free periods may be long in temperate regions due to the short annual cycles of local fruit and vegetable hosts (Fig. 1b). We side-step the complications of multiple host phenologies by using a composite model (Fig. 1c) that produces a short but variable host free period at all locations. This is accomplished by shortening the time to bloom by half, and by lengthening the developmental time of susceptible fruit by $20 \%$.

Medfly lacks a diapause stage, but some adults are long-lived (Carey et al. 2008), with some living more than 200 days at cool temperatures (Rigamonti 2004). As in other fruit flies, females may enter reproductive quiescence when hosts are in short supply or temperatures are high, but quiescence may be reversed when favorable host and/or weather conditions return (Gutierrez et al. 2009). Below we estimate the temperature dependent rates of development, mortality and fecundity in medfly.

\section{Estimating developmental rates}

Data on egg (Messenger and Flitters 1958; Delrio et al. 1986) (Fig. 2a) and pupal (Corvetti et al. 1986; Vargas et al. 2000) (Fig. 2b) development were used to estimate the non-linear development rates $(R(T)=1 /$ days $(T))$ on temperature $(T)($ Eq. 1 ; Brière et al. 1999).

$$
\begin{gathered}
R_{\text {egg }}(T)=\frac{0.031 \cdot(T-10.5)}{1+b^{(T-35.5)}} \\
R_{\text {pupae }}(T)=\frac{0.006 \cdot(T-9.5)}{1+b^{(T-34.5)}}
\end{gathered}
$$

The lower thresholds for the egg and pupal stages are 10.5 and $9.5^{\circ} \mathrm{C}$, respectively, while the temperatures where the functions begin to decline toward zero are 35.5 and $34.5^{\circ} \mathrm{C}$. Data on larval and adult development were insufficient to estimate their thresholds, hence the thresholds for the egg stage were used for the larval stage, and the pupal thresholds were used for the adult stage (see Vargas et al. 2000). Data reported by Shoukry and Hafez (1979) at $25^{\circ} \mathrm{C}$ were used to estimate the developmental times $\left(\Delta_{s}\right)$ in degree days $\left(\mathrm{dd}_{\mathrm{s}}\right)$ above the lower threshold for each life stage (subscript $s$; Table 1). Time and age in the model are in physiological time units (degree days, $\mathrm{dd}$ ), with daily $(t)$ stage-specific increments computed as $\Delta \operatorname{dd}_{s}(t, T)=\Delta_{s} \times R_{s}(t, T)$. 
Fig. 2 Medfly

development and mortality rates per day on temperature for eggs (a, $\mathbf{c}$ data from Messenger and Flitters 1958; Delrio et al. 1986), pupae (b, $\mathbf{d}$ data from Corvetti et al. 1986; Vargas et al. 2000), and (e) adults (Vargas et al. 1997). The mortality functions for eggs and pupae are included in (e) for comparative purposes. The datum, symbol white circle in c, was estimated from Powell (2003)
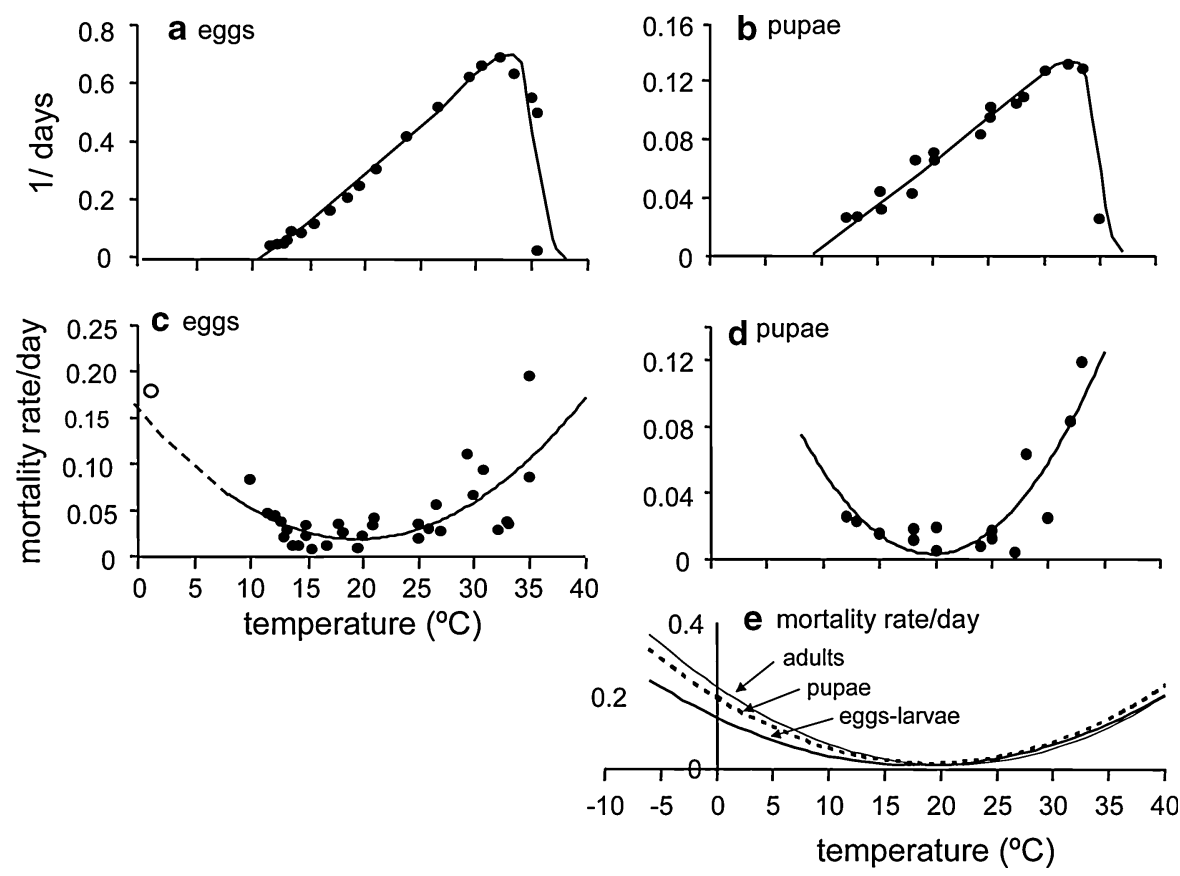

\section{Mortality rates}

Daily temperature-dependent mortality rates for eggs $\left(\mu_{\text {egg }}(T)\right)$ were estimated using data from Messenger and Flitters (1958) and Delrio et al. (1986) (Fig. 2c; Eq. 2i). The mortality rates for the larval stage are assumed to be the same as for the egg stage. This assumption is supported by the 0.185 rate at $1{ }^{\circ} \mathrm{C}$ estimated by Powell (2003) for the combined egglarval period (symbol $\mathrm{O}$ in Fig. 2c). Data from Corvetti et al. (1986) and Vargas et al. (2000) were used to estimate pupal mortality $\left(\mu_{\text {pupae }}(T)\right)$ (Fig. 2d; Eq. 2ii), while the adult rate $\left(\mu_{\text {adults }}(T)\right.$, Eq. 2 iii) was estimated from Vargas et al. (1997). The lowest mortality rate for each stage occurs at $T_{\mathrm{opt}}$, which can be estimated by solving for $T$ at $\partial \mu_{s} / \partial T=0$ (Eq. 2). This yields $T_{\mathrm{opt}}$ values of $18.1^{\circ} \mathrm{C}$ for the egg-larval stage, $20.7^{\circ} \mathrm{C}$ for pupae, and $19.2^{\circ} \mathrm{C}$ for adults.
Table 1 Some biological parameters for the Mediterranean fruit fly model

\begin{tabular}{ll}
\hline Initial medfly population & 50 pupae/tree \\
\hline $\begin{array}{l}\text { Duration of life stages in } \\
\text { degree days }\end{array}$ & Eggs $\left(31 \mathrm{dd}>10.5^{\circ} \mathrm{C}\right)$ \\
& Larvae $\left(97 \mathrm{dd}>10.5^{\circ} \mathrm{C}\right)$ \\
& Pupae $\left(165 \mathrm{dd}>9.5^{\circ} \mathrm{C}\right)$ \\
& Pre-ova $\left(48 \mathrm{dd}>9.5^{\circ} \mathrm{C}\right)$ \\
& Adults $\left(673 \mathrm{dd}>9.5^{\circ} \mathrm{C}\right)$ \\
& Quiescent females $(1050 \mathrm{dd}$ \\
& $\left.>9.5^{\circ} \mathrm{C}\right)$ \\
Immigration & $0.5 \times 10^{-7}$ females $/$ day \\
Sex ratio & $1: 1$ \\
Delay parameter $(k)$ & 15 for eggs and larvae \\
& 40 for pupae and adults \\
\hline
\end{tabular}

Survival of a cohort $\left(N_{s, O}\left(t_{0}\right)\right)$ of stage $s$ and age $O$ during its developmental period $\left(t_{0}\right.$ to $t_{f}$ ) is computed as:

$0 \leq\left\{\begin{array}{l}\mu_{\text {egg-larval }}=0.0004 T^{2}-0.0145 T+0.1314, \quad r^{2}=0.46, \quad n=31 \quad \mathrm{i} \\ \mu_{\text {pupae }}=0.0005 T^{2}-0.0207 T+0.2142, \quad r^{2}=0.76, \quad n=15 \quad \text { ii } \\ \mu_{\text {adult }}=0.00049 T^{2}-0.0187 T+0.1846, \quad r^{2}=0.95, \quad n=5 \quad \text { iii }\end{array}\right.$ 
$N_{s}\left(t_{f}\right)=N_{s, o}\left(t_{0}\right) \prod_{t=t_{0}}^{t_{f}}\left(1-\mu_{s}(T(t))\right)$.

\section{Reproduction}

Estimates of medfly fecundity in the literature vary widely due to age, size, temperature and food availability (Krainacker et al. 1987), but only the effects of age and temperature could be estimated from data. Per capita age-specific fecundity profiles ( $f(x, T), x=$ age; see Bieri et al. 1983) were reported by Muñiz and Gil (1986) at several temperatures (Fig. 3a), and by Shoukry and Hafez (1979) at $25^{\circ} \mathrm{C}$. Estimates of net gross fecundity from Muñiz and Gil (1986) are roughly twice those reported by Vargas et al. (1997) at the same temperature, and three time that from Shoukry and Hafez (1979). The underlying patterns are similar as can be seen by plotting the normalized data $(0 \leq \phi(T) \leq 1)$ on temperature (Fig. 3b; Eq. 4i), where $\phi(T)$ is zero at $T_{\min }=15^{\circ} \mathrm{C}$ and $T_{\max }=32^{\circ} \mathrm{C}$, and unity at $T_{\text {mid }}=23.5^{\circ} \mathrm{C}$.

$0 \leq \phi(T)=1-\left(\frac{T-T_{\text {min }}-T_{\text {mid }}}{T_{\text {mid }}}\right)^{2} \leq 1$
The combined effects of age and temperature on fecundity $(F(x, T))$ was estimated as the product of the Muñiz and Gil (1986) fecundity profile $(f(x, T))$ at $T=22^{\circ} \mathrm{C}$ and $\phi(T)$ (Eq. 4ii; Fig. 3c).

$F(x, T)=\phi(T) f\left(x, T=22^{\circ} \mathrm{C}\right)=\phi(T) \frac{0.43 x}{1.006^{x}}$.

Mating frequency in medfly declines with age and is concave on temperature, being zero at 22.5 and $30.5^{\circ} \mathrm{C}$ (Liedo et al. 2002). We conservatively assume all females are mated, and that the sex ratio is 1:1.

Weather data

Daily max-min temperatures and solar radiation data from 151 locations in AZ-CA for the period 1995-2006 (http://www.ipm.ucdavis.edu/), and 84 locations in Italy for the period 1999-2005 (http:// www.ucea.it/) were used to run the model. The few missing values in the AZ-CA weather records were estimated by linear interpolation within the data or using data from near by locations. Missing values in the Italian data were estimated using inverse distance
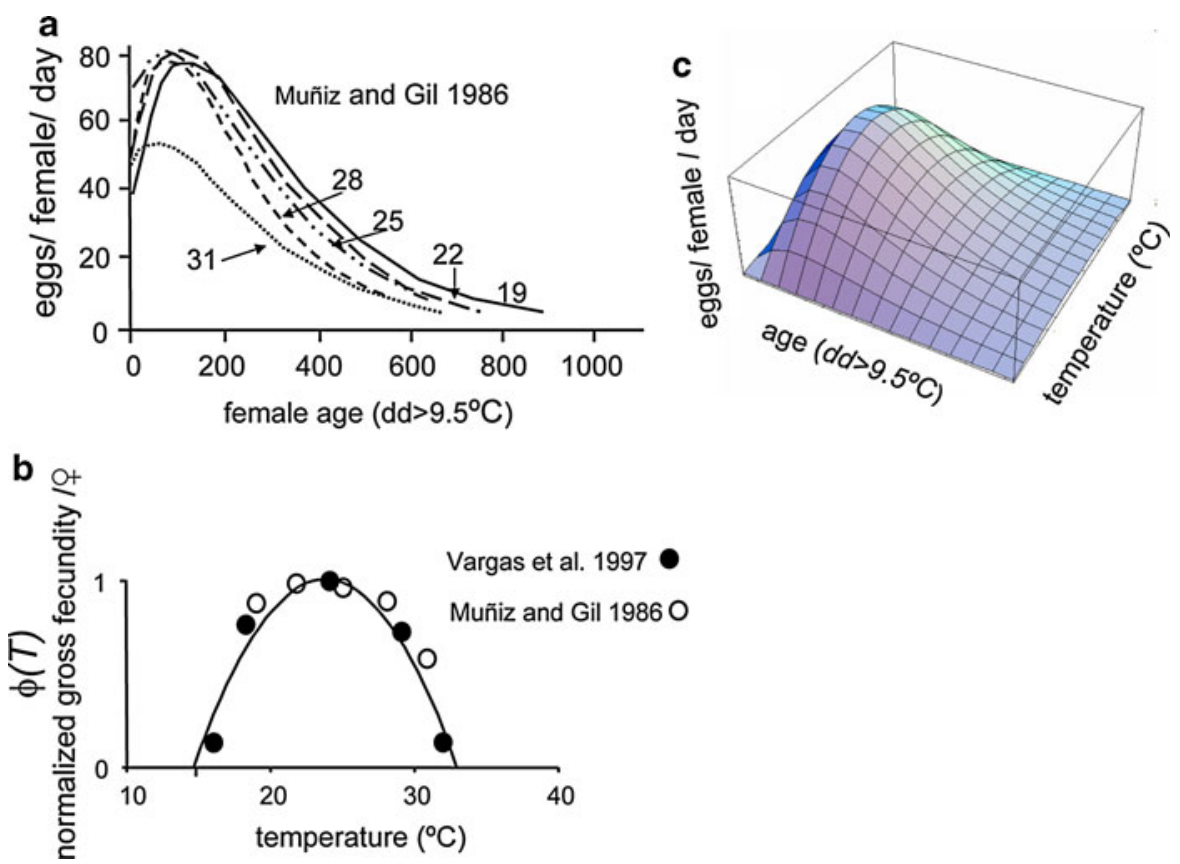

Fig. 3 Age-specific, temperature-dependent fecundity of medfly females: a the per capita age-specific oviposition profiles $(f(x, T))$ on degree days $>9.5^{\circ} \mathrm{C}$ at $19,22,25,28$ and $31^{\circ} \mathrm{C}$
(Muñiz and Gil 1986), b normalized gross fecundity/9 on temperature $(\phi(T)$; Vargas et al. 1997; Muñiz and Gil 1986), and $\mathbf{c}$ the product of $\phi(T)$ and $f\left(x, T=22^{\circ} \mathrm{C}\right)$ 
weighting interpolation of data from the surrounding locations (Mita and Mitasova 2002).

Global climate models predict that California will become warmer $\left(1.8-3^{\circ} \mathrm{C}\right.$ or more), but not drier with precipitation rather than snowfall occurring at higher elevations (http://meteora.ucsd.edu/cap/pdffiles/CA_ climate_Scenarios.pdf; Hayhoe et al. 2004). Italy and the Mediterranean Basin are predicted to become warmer and drier (Ponti et al. 2009). A full study of climate change effects using climate model data is beyond the scope of this study, and hence we examine only the hypothetical effects of +2 and $+3^{\circ} \mathrm{C}$ increases in average temperature on potential medfly distribution.

\section{Simulation and GIS mapping}

Using a batch file, the model was run continuously for the period of available weather data, using the same initial conditions for all locations in AZ-CA and Italy (see Table 1). Annual pupae tree ${ }^{-1}$ year $^{-1}$ at all locations, and the mean and coefficient of variation ( $\mathrm{CV}$ as a proportion) across years were used as metrics of favorability. Data from the first year of simulation were not used to compute means and CVs because the model was assumed equilibrating to local conditions. Cumulative daily mortality above and below the optimum temperature $\left(T_{\mathrm{opt}}=18.2^{\circ} \mathrm{C}\right)$ for the egg-larval stage was used as an additional metric to assess favorability.

Data (pupae tree $^{-1}$ year $^{-1}$ ) from all locations below $750 \mathrm{~m}$ elevation were mapped using the open source GIS software GRASS (Geographic Resources Analysis Support System). GRASS is maintained and being further developed by the GRASS Development Team (2010) (http://grass.osgeo.org). Inverse distance weighting interpolation was used in mapping the data. We caution that the numerical results should be viewed only as relative measures of favorability.

\section{Results}

Arizona-California

Simulation results for $\mathrm{AZ}$ were near zero suggesting that temperatures there are outside of medfly's climatic envelope, and hence AZ is not included in the GIS maps.
Total annual pupae tree $^{-1}$ year $^{-1}$ for the period 1996-2005 in CA (Fig. 4a-j) varied considerably both geographically and across years. The vertical histograms in each sub-figure are for comparison of density ranges across years relative to 1999. Low populations are predicted everywhere during 1996, while during 1997-2005, moderate to high populations are predicted only in south coastal CA (Los Angeles, Orange and San Diego Counties) (Fig. 4j). This is the area where medfly has been consistently discovered since 1975 (Myers et al. 2000, see below). Much of the agriculturally rich Central Valley is predicted unfavorable during 1996, 1997, 1998, 1999, 2001, 2003 and 2005, and only marginally favorable during 2002 and 2004. Predicted populations in the Central Valley are roughly $15-25 \%$ those in south coastal CA.

Maps of average pupal densities (Fig. 5a) show low average favorability across most of CA except in south coastal CA. The CVs are measures of intra-annual variability, and are lowest in south coastal CA, moderate in the Central Valley, and highest in the south desert regions and the northern reaches of coastal CA (Fig. 5b). Medfly establishment and persistence requires continuous inter-annual favorability, and this could occur only in the south coastal region.

\section{Medfly discoveries in $C A$}

The yearly discoveries of medfly in CA during the period of 1975-2007 are shown in the insets to Fig. 5a (symbol •; data from J.R. Carey. http:// entomology.ucdavis.edu/news/califmedfliescities.html). A high concentration of discoveries occurred in the Los Angeles Basin, an area predicted to be favorable (Figs. 4, 5). Most of the early discoveries (1975, 1980, and 1981) occurred in Northern California (Fig. 5c) in the marginally favorable area of Santa Clara County just south of San Francisco Bay (Fig. 5a, b). Note that only occasional discoveries were made after 1980 in Northern CA (Fig. 5c). Below, we examine these discoveries more closely.

The limiting effects of low and high temperatures during the period 1996-2005 can be estimated as the average of the annual sum of daily mortality rates above $\left(\bar{M}_{A}\right)$ and below $\left(\bar{M}_{B}\right)$ the optimal temperature $\left(T_{\text {opt }}=18.1^{\circ} \mathrm{C}\right.$ ) for the egg-larval stage (Eq. $\left.2 \mathrm{i}\right) \cdot \bar{M}_{B}$ in the south coastal and desert regions of CA is twothree fold lower than in the Central Valley and 

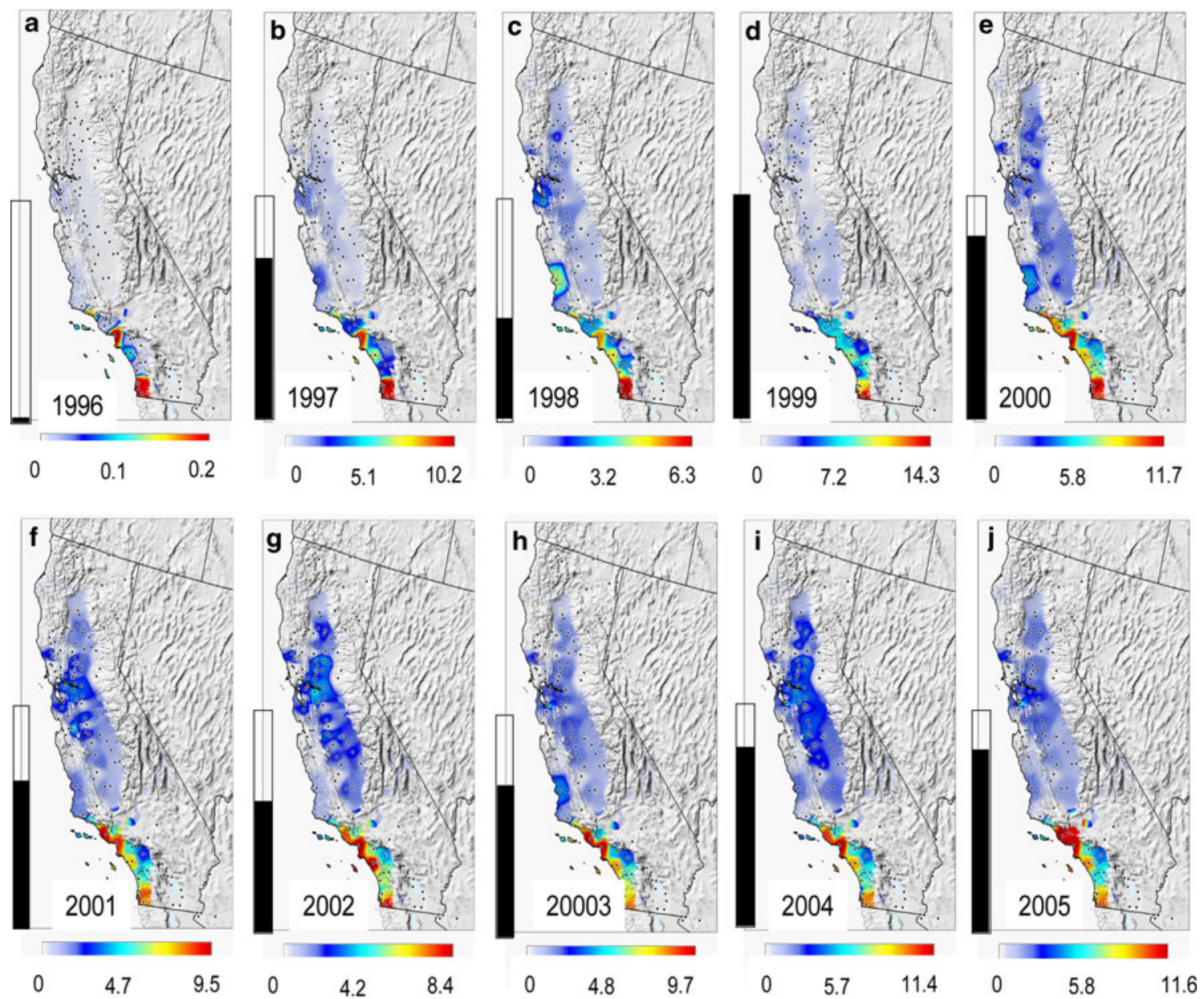

pupae $\mathrm{y}^{-1}\left(\mathrm{x} 10^{3}\right)$

Fig. 4 Annual maps of simulated medfly pupae tree ${ }^{-1}$ year $^{-1}$ across California during 1996-2005 (a-j). Data from Arizona are not shown (see text). The vertical histogram in each sub-

northern CA (Fig. 6a). Specifically, $\bar{M}_{B}$ (CV) for three reference location (Santa Ana, San Diego and Santa Monica) in south coastal CA are 1.34 (0.29), 1.29 (0.48) and $1.11(0.30)$, respectively. In contrast, $\bar{M}_{B}$ for San Jose was $2.92(\mathrm{CV}=0.15)$, while that for Fresno in the Central Valley was $3.66(\mathrm{CV}=0.18)$. During the warmer period, $\bar{M}_{A}$ in south coastal CA was less than 0.6 , while many areas of the Central Valley were three to five folds higher, and those in the desert areas of southern CA were considerably higher (Fig. 6b). Only south coastal CA was favorable with respects both metrics.

We now use this information as a standard for examining favorability at San Jose during 1975 and figure represents the relative range of densities compared to the maximum during 1999

1979-1982 when several discoveries of medfly occurred. Using spreadsheet calculations for Eq. $2 \mathrm{i}$, we find that $\bar{M}_{B}$ was 4.84 in $1975,3.35$ in 1979, 2.89 in 1980, and 2.64 in 1981, and 4.24 in 1982. The values during 1980 and 1981 at San Jose are more than twice the average for the three reference locations in south coastal CA. This suggests that San Jose is only marginally favorable for medfly.

We summarize all of the pupal simulation data for CA during 1996-2005 using multiple regression, retaining in the model only independent variables and interaction terms with slope significantly different from zero (Eq. 5). 

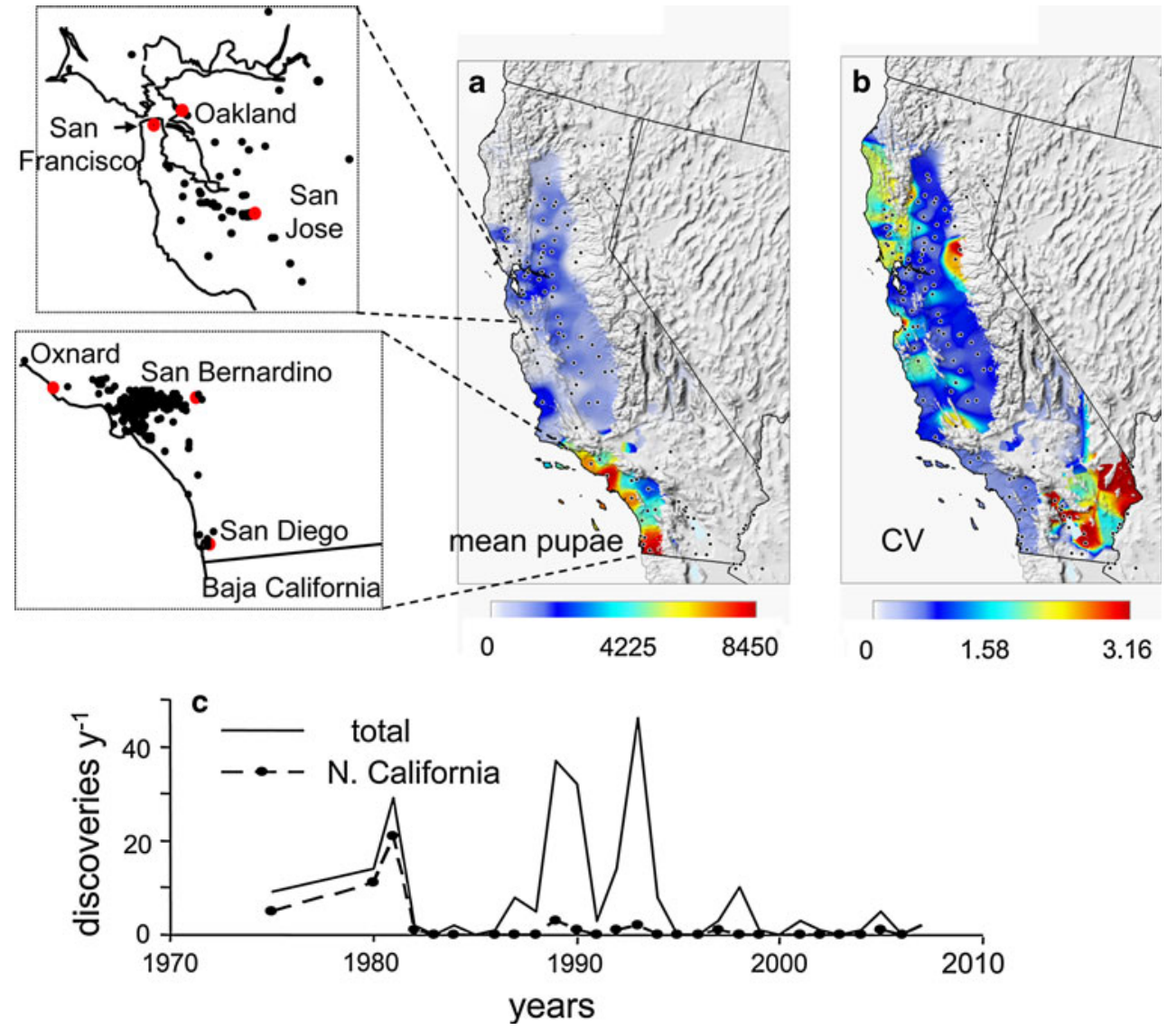

Fig. 5 Geographic distribution of medfly in California: a average pupae tree year $^{-1}$ during 1996-2005 with insets for annual medfly discoveries (black circle) during 1975-2007 in northern and southern California; $\mathbf{b}$ coefficient of variation ( $\mathrm{CV}$ as a proportion) of average pupae tree $\mathrm{year}^{-1}$ during

$$
\begin{gathered}
\log _{10} \text { pupae }=0124+00019 \mathrm{dd}-4.7 \times 10^{-3} \mathrm{Fr} \\
-0423 \bar{M}_{A}-0339 \bar{M}_{B} \\
R^{2}=0.541, d f=1356, F=398.4
\end{gathered}
$$

The effects of season length for the host (dd, $P<0.01)$ is positive, while the effects of fruit number $(\operatorname{Fr}(P<0.05)), \bar{M}_{A}(P<0.01)$ and $\bar{M}_{B}$ $(P<0.01)$ are negative. Only the small negative effect of fruit numbers was unexpected. The mean values for the independent variables are $\mathrm{dd}=2320$, Fr $=5906, \bar{M}_{A}=2.23$ and $\bar{M}_{B}=4.00$. Substituting the mean values in Eq. 5, we find that on average, given the average effect of the other factor, the effect of $\bar{M}_{A}$ is 0.75 that of $\bar{M}_{B}$. This reflects the greater impact of cold temperatures on medfly in CA. However, including the AZ data in the analysis,
1996-2005; c the number of locations per year where medfly were discovered in CA during the period 1975-2007. The data in the insets and c are from J.R. Carey (University of California, Davis) (http://entomology.ucdavis.edu/news/ califmedfliescities.html)

shows that the average effect of $\bar{M}_{A}$ is 2.5 fold greater than that of $\bar{M}_{B}$ (analysis not shown).

In summary, only the coastal counties of southern CA may be favorable for medfly. Most areas of northern and central CA are limiting due to low to freezing temperatures, while the desert areas of southern CA and AZ are limiting due to high summer temperatures. Permanent establishment of medfly in the Central Valley would appear unlikely under current weather conditions. Last, we are unable to explain the early discoveries of medfly at San Jose.

Italy

The fly has been established in Italy for decades, but data on its distribution are not available. Medfly 
Fig. 6 Mean cumulative daily mortality rates per year for the egg-larval stage (see Fig. 2): a below and b above the optimal temperature of $18.1^{\circ} \mathrm{C}$. The inset to $\mathbf{a}$ is for the San Francisco Bay area

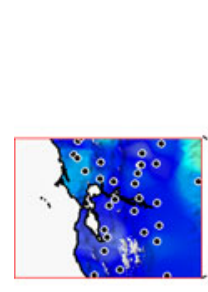

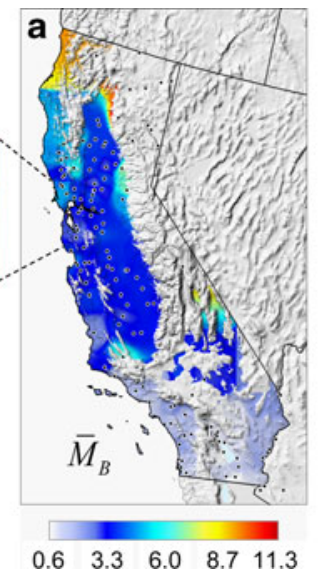

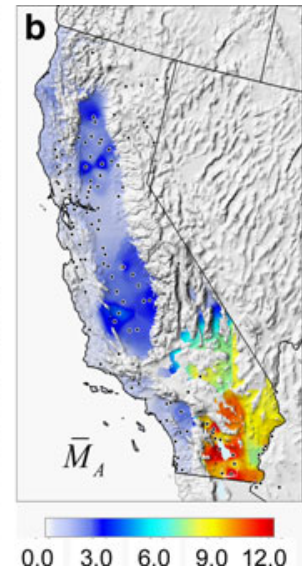

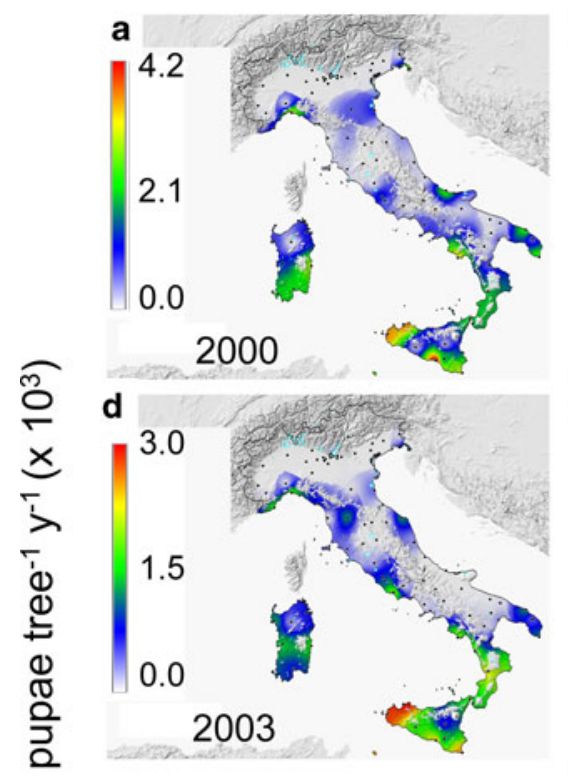
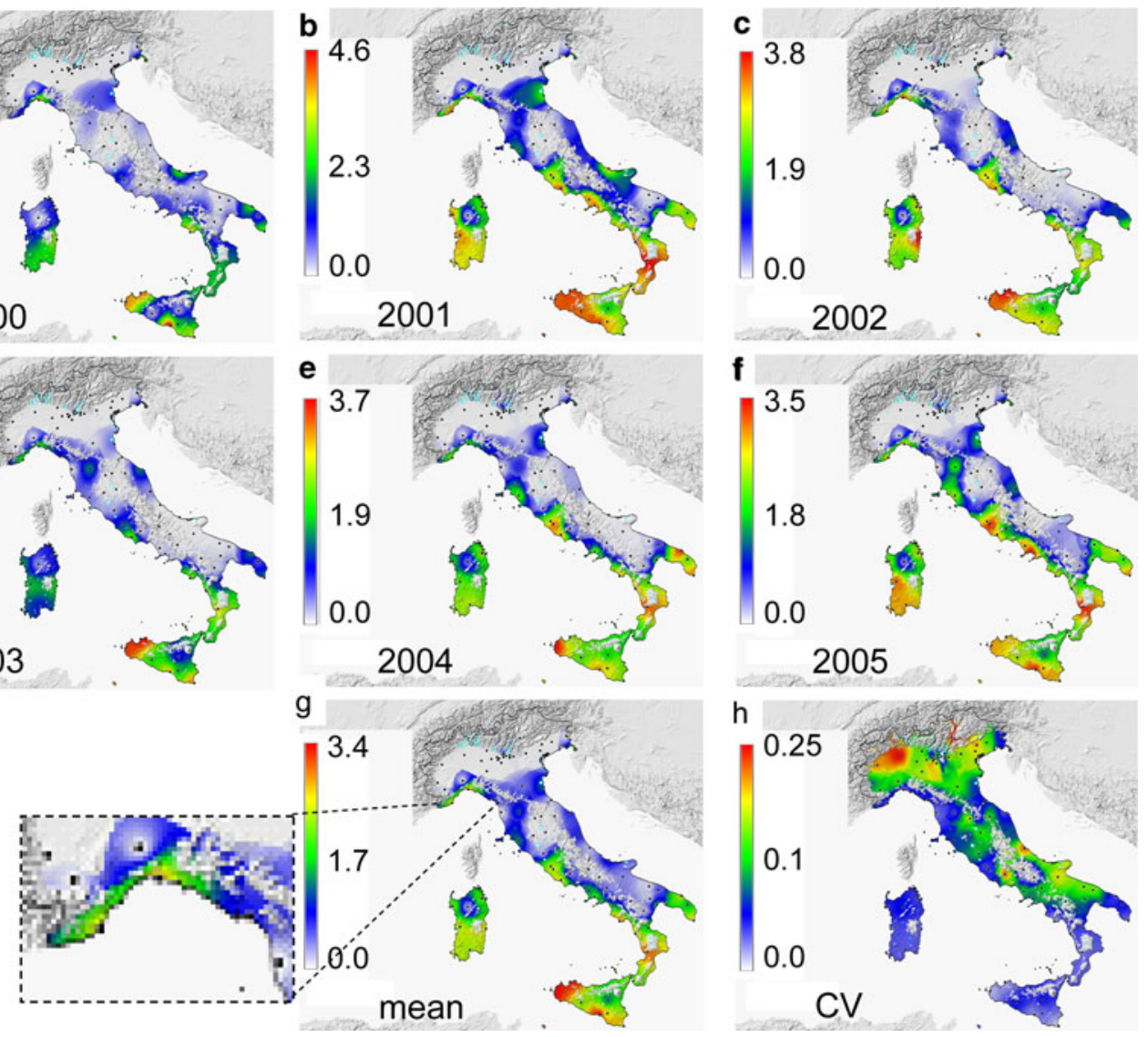

Fig. 7 The simulated geographic distribution and relative abundance of medfly (pupae tree ${ }^{-1}$ year $^{-1}$ ) in Italy during 2000-2005 (a-f), (g) mean density (see inset for Liguria), and (h) the coefficient of variation (CV as a proportion)

expert Ivo Rigamonti (University of Milan, personal communication) wrote: "Medfly is established in southern and central Italy; in northern Italy there seems to be only a sporadic presence in Lombardia where it may occur in peri-urban areas where small farms or home gardens may offer a sequence of 
different fruits during the year, and where temperature may be higher than in the surroundings countryside" (see also Delrio 1986).

The predictions of our model for Italy during 1999-2005 (Fig. 7a-f) are in accord with these observations. Stable high populations are predicted along the coast near Rome, the southern half of Sardinia, much of Sicily, the southern areas of the Italian peninsula, and the mild climatic region of Liguria in the northwest of Italy (see inset to Fig. $7 \mathrm{~g}$ ). Medfly is predicted absent most years along the eastern coast of the Italian peninsula, in the Apennine Mountains, and the plain of the Po River (Lombardia and Emilia-Romagna). Areas predicted to have high mean levels of medfly (Fig. $7 \mathrm{~g}$ ) also have associated low CVs (Fig. 7h).

\section{Climate warming}

Increasing temperatures +2 and $+3{ }^{\circ} \mathrm{C}$ would expand the area of favorability for medfly northward along the coast of CA, but parts of south coastal CA that are currently favorable would become less favorable
(Fig. 8a vs. b, c). The Central Valley and the hot desert regions of AZ-CA would remain inhospitable. In Italy, the area of favorability is also predicted to increase northward with increasing temperatures (e.g., Tuscany), while the southern part of Sardinia, Sicily and Calabria would become less favorable.

\section{Discussion}

Limiting the introduction of invasive species is of paramount importance, but once a new species is discovered, accurately estimating its potential invasiveness, geographic distribution, and the feasibility of eradication (Parker et al. 1999) are key to preserving natural and economic capital (Clark et al. 2001). The tropical Mediterranean fruit fly (medfly) is a classic example of an invasive species that garnered considerable scientific, economic, and political attention; especially in California where it remains of vital concern 35 years after it was first detected.


Fig. 8 Simulated average medfly pupae tree year $^{-1}$ in California (1996-2006) and Italy (2000-2005) using observed temperatures (obs.), and increasing observed daily max-min temperatures +2 and $+3^{\circ} \mathrm{C}$ 
Carey (1996b) posited that wide medfly infestation could occur in CA based on the assumptions that it is established in the state; existing eradication technologies are inadequate; no new and effective eradication technology will be developed in the near future; and the caveat that population will not become extinct due to natural causes. Micro-satellite and mitochondrial DNA (mtDNA) data confirm that multiple introductions of medfly occurred during 1992-1994 and 1997-1999 (Meixner et al. 2002), and if medfly is established, could increase its genetic variability, and possibly its potential invasiveness (Malacrida et al. 2007). Medfly populations from different areas of the world exhibit two-fold differences in life span and have different reproductive allocation (Diamantidis et al. 2008). Females appears to enter reproductive quiescence that greatly increases longevity (Carey et al. 2008), and larval development in hosts such as apples is longer, and combined with low temperatures may allow winter survival (Papadopoulos et al. 2002) in marginal areas. These attributes enhance the fly's ability to establish and persist.

However, despite multiple introductions in CA, medfly has not spread nor reached pest levels. Is this because eradication efforts were uniformly successful in CA? We suspect that is not the case. Field studies by Israely et al. (2004) show that the tropical medfly does not over-winter in the Judean Hill of central Israel because of its susceptibility to moderately cold temperatures. This finding of cold intolerance accords with our analysis for CA.

\section{Medfly in California and Italy}

Our model predicts that the area of potential favorability is the south coastal region of CA, and especially the urban areas of the Los Angeles basin, where medfly has frequently been discovered (Fig. 5a). Some areas of the state may be suitable during part of the years (e.g., Santa Clara County during 1980-1981), but not continuously over several years as required for persistence. Our analysis suggests that temperatures in much of CA are simply outside of medfly's thermal envelope. However, medfly discoveries in CA will likely continue due to new invasions (Meixner et al. 2002), and possibly survival in urban microclimates (e.g., the Los Angeles Basis), infestations in stored hosts, and their transport to new areas (Rigamonte 2004), and to others causes. We suspect that if the fly is established in CA, its permanence is tenuous. In contrast, medfly is established in Italy, and our model predicts the wide geographic favorability observed there (Fig. $7 \mathrm{~g}$ ).

\section{Eradication of invasive species}

Eradication campaigns, such as that for medfly, have occurred without the benefit of sound analysis of the pest's potential geographic distribution, invasiveness, or damage potential. When medfly entered California, decision makers were unable to determine important areas of uncertainty, identify and interpret feedback ("expert opinion"), or respond adaptively to the evolving problem (Lorraine 1999). We feel that little changed, as eradication policy for new invasive species continues to be formulated in an alarmist mode, with decision makers continuing to ignore science that conflicts with their policies. For example, USDA and CDFA point to the supposed containment/ eradication of the tropical pink bollworm (Pectinophora gosypiella (Saunders), PBW) in the Central Valley of CA to justify ongoing efforts against this pest. They ignore evidence that PBW scarcity in the Central Valley is due to its high susceptibility to winter temperatures there, and to transgenic Bt cotton widely cultivated in desert areas (Gutierrez et al. 2006a). Before Bt cotton, desert cotton was the source of abundant late-summer migrants to the lower Central Valley. Similar arguments are used to justify the estimated $\$ 300+$ million spent in CA to contain/ detect/eradicate medfly. The general absence of the fly is viewed as validation of policy, while the possibility that medfly is unable to establish widely in CA, appears not to be considered.

The polyphagous light brown apple moth (LBAM, Epiphyas postvittana (Walk.) was detected in northern CA in 2007, and a $\$ 100$ million eradication program was begun based on its predicted wide distribution, and an assumed high potential for damage (Fowler et al. 2009). Public outcry and pressure to stop the area-wide spraying, as well as research indicating LBAM was a manageable economic threat with a restricted distribution along the coast, helped to stop/delay the program (Gutierrez et al. 2010). In 2008, the European grape vine moth (Lobesia botrana (Den. and Schiff.)), a common pest of grape in the Mediterranean area, was found in Napa County in the heart of California's wine country. Lobesia quickly spread to six additional 
counties, including the Central Valley, and analysis suggests it will spread statewide and beyond (Gutierrez et al. submitted). How this problem will be addressed remains an open question.

Predicting the geographic range of species

What is clear is that science-based predictions to assess the invasive potential of new and extant pest species should be of high priority. But, there is also need for open discussion about the appropriateness of the methodologies used to make these assessments. Ecological niche models (ENMs) are commonly used to characterize the climate envelope of an invasive species based on weather and other factors in the areas of its native distribution, and then to project its potential distributions in new areas. Some caveat assumptions of ENMs are that the current distribution is the best indicator of a species' climatic requirements, the distribution is in equilibrium with current climate, and climate niche conservatism is maintained in both space and time (Beaumont et al. 2009). Deficiencies of ENMs include difficulty of incorporating trophic interactions (Davis et al. 1998), aggregate weather data are often used that miss important short-term weather effects, the assumed native distribution may be in error, and the different methods may give different predictions. For example, RouraPascual et al. (2009) compared five ENM methods to predict the potential distribution of the Argentine ant in the Iberian Peninsula, and found differences in geographic prediction, and in the ability to identify areas of uncertainty regarding invasive potential. De Meyer et al. (2008) used PCA and GARP, and Vera et al. (2002) used the CLIMEX algorithm to map the global distribution of medfly, but the coarse grain of their predictions for California and Italy were difficult to assess and compare to the fine scale results of our model. The De Meyer et al. (2008) GARP study predicts temporary establishment of medfly in CA, but it is difficult to say exactly where. The Vera et al. (2002) study predicts a much wider geographic range for medfly under irrigation in CA including the Central Valley. Our results for CA are more in line with the GARP study. For Italy, the average predictions of the three models are more similar with the predictions of De Meyer et al. (2008) being geographically broader.
Like Sutherst and Bourne (2009) and Sutherst et al. (2007, 2009), we argue for the development of mechanistic models capable of progressive enhancement, to assess the distribution of invasive species. The CASAS approach is mechanistic, and has early roots in the ideas of Fitzpatrick and Nix (1968) and de Wit and Goudriaan (1978). The approach accommodates age-mass-structured dynamics, behavior, dormancy, tri-trophic interactions, the effects of short-term weather, and other factors (Gutierrez and Baumgärtner 1984).

The models have a modest numbers of measurable parameters (see text and Table 1), and have theoretical and mathematical coherence (see "Appendix"). The model structure is similar across taxa, and has been applied to the analysis of the distribution and abundance of an invasive weed (e.g., the noxious yellow starthistle; Gutierrez et al. 2005) and insect species (Gutierrez et al. 2006a, b, 2008a. b, 2009, 2010; Ponti et al. 2009). In all of these cases, sound biological data were required to parameterize the models. While this is a strong point, such data may not be available at the onset of an invasion, and this may delay or prevent application of the approach. On the positive side, the modeling framework provides clear guidance for identifying data needs, and for guiding data collection. In the best case, once completed, the model may be used as an economic objective function (Gutierrez and Regev 2005; Pemsl et al. 2007) in the evaluation of the biological and economic impact of an invasive species on a region-wide basis.

Acknowledgments We are grateful to Dr. M. Neteler (Fondazione Edmund Mach-Centro Ricerca e Innovazione, Trento, Italy; http://gis.fem-environment.eu/) and the international network of co-developers for maintaining the Geographic Resources Analysis Support System (GRASS) software, and making it available to the scientific community. The insightful suggestions of two anonymous reviewers were invaluable.

Open Access This article is distributed under the terms of the Creative Commons Attribution Noncommercial License which permits any noncommercial use, distribution, and reproduction in any medium, provided the original author(s) and source are credited.

\section{Appendix: Model overview}

Common processes occur across trophic levels that allow the same functional (resource acquisition) and 
population dynamics models to be used to describe the dynamics of all consumer species in a system, including the plant (Gutierrez and Baumgärtner 1984; Gutierrez 1992). All organisms acquire and allocate resources (i.e. the supply, $S$ ) in priority order to egestion, conversion costs, respiration (i.e., the $Q_{10}$ rule in poikilotherms), and to reproduction in adults and/or growth and reserves.

\section{The functional response}

Differences between a true predator that seeks biomass (e.g., the plant) and a parasitoid that seeks individual packets of biomass (e.g., medfly) exist, but can be easily accommodated by the model. The biology of biomass acquisition is modeled using a ratio-dependent functional response model where the sum of per capita maximal genetic assimilation demands (or host numbers) $(D)$ is the major parameter.

Per capita acquisition in a time-varying environment is a search process, and to estimate acquisition success, we use the demand-driven ratio-dependent Gutierrez and Baumgärtner (1984) functional response model (Eq. 6). At consumer population level $N$, the resource acquisition rate is

$\mathrm{SN}=\operatorname{Dh}(u)=\mathrm{DN}\left[1-\exp \left(\frac{-\alpha(N) R}{\mathrm{DN}}\right)\right]$

The search rate function $((0<\alpha(N)=1-\exp$ $\left.\left(-\alpha_{0} N\right)<1\right)$ is the proportion of resource $R$ that may be potentially found by $N$ at time $t$.

For plants, $\alpha(N)$ is a function of leaf mass $N$ that multiplied by a constant yields leaf area, and $R$ is solar radiation (e.g., cal $\mathrm{cm}^{-2} \mathrm{day}^{-1}$ ) that multiplied by a constant is converted to $\mathrm{g} \mathrm{cm}^{-2}$ day $^{-1}$. This is a type III functional response model. $D$ may be estimated per unit of $N$ under conditions of nonlimiting resource by solving for $D \approx S_{\max }$ (i.e., the metabolic pool model; Eq. 7; Gutierrez and Baumgärtner 1984).

$D \approx S_{\max }=\left(G R_{\max }(t) / \lambda+Q_{10}\right) / \beta$

$G R_{\text {max }}$ is the maximum growth/reproductive rate, $\lambda$ is the conversion rate of a unit $R$ to unit of $N, \beta$ is the egestion rate, and $Q_{10}$ is the respiration rate. We note that $D$ in the model may vary with age, stage, sex, size, temperature and other factors. Dividing both sides of (Eq. 6) by $D N$ yields the supply-demand ratio $\left(0 \leq \phi_{S / D}=S / D<1\right)$ (Gutierrez et al. 1994).

Like a parasitoid, medfly seeks individual units (host fruit) with the demand being the number of hosts it can attack. The dynamics model for medfly incorporates the simplifications outlined in the text that capture the S/D effects. For example, the concave function $\phi(T)$ (text Eq. 4i) scales fecundity from the maximum value, and may be viewed as the normalized difference between the acquisition rate corrected for egestion and conversion costs, and the metabolic rates.

\section{The dynamics model}

The biology of the plant and medfly is embedded in an Erlang distributed-maturation-time demographic model that simulates the dynamics of age structured populations (Vansickle 1977; see DiCola et al. (1999, pp 523-524). The general model for the $i$ th age class of a population is

$\frac{\mathrm{d} N_{i}}{\mathrm{~d} t}=\frac{k \Delta x}{\Delta}\left[N_{i-1}(t)-N_{i}(t)\right]-\mu_{i}(t) N_{i}(t)$

$N_{i}$ is the density of the $i$ th age class, $\mathrm{d} t$ is the change in time (dd/day), $k$ is the number of age classes, $\Delta$ is the expected mean developmental time, $\Delta x$ is a daily increment in age $(x)$, and $\mu_{i}(t)$ is the proportional net loss rate (inflows minus outflows) due all factors (e.g., births, deaths, etc.).

Plant subunits require separate models that are linked via daily photosynthetic flow. These subunit models may have attributes of number and/or mass as appropriate. All medfly life stages (numbers) can be included in one dynamics model, with eggs produced by the adults age classes entering the first age cohort $\left(N_{l}(t)\right)$ as $x_{0}(t)$ (Fig. 9a). The flow rates $\left(r_{i}(t)\right)$ between age classes $i=1, \ldots, k$ depends on the numbers in the previous age class and dd/day, with the distribution of final maturation times (Fig. 9b) determined by the number of age classes $k$ defined by the mean maturation time $\Delta$ and variance (var) (i.e. $k=\Delta^{2} /$ var). The larger the value of $k$, the narrower is the Erlang distribution of developmental times.

For convenience, separate models are used for the different life stages ( $\mathrm{s}=$ egg, larval, pupa, adult), with each having stage specific characteristics (e.g. $\left.\Delta_{\mathrm{s}}, k_{\mathrm{s}}, \ldots\right)$, and with the outflow of the last age class 
Fig. 9 The distributed maturation time model: a all life stages in one model, b the frequency distribution of maturations times with different numbers of age classes $(k)$, and $\mathbf{c}$ separate models for each life stage each having the between stage flow biology depicted in (a)
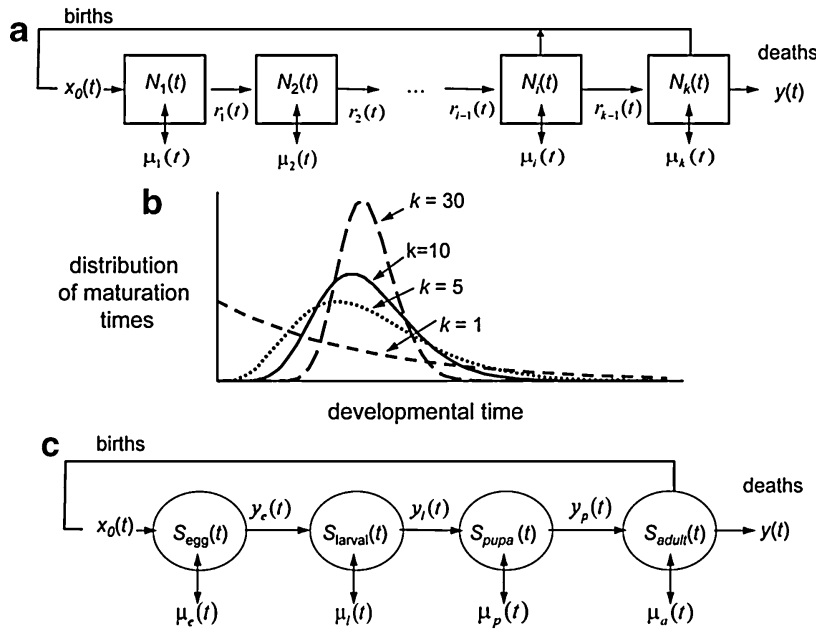

of a stage $\left(y_{i}(t)\right)$ entering the first age class of the next stage $\left(x_{i+1,0}(t)\right)$. All eggs produced by the adults enter the first age class of eggs as $x_{0}(t)$ (Fig. 9c). A separate model for reproductively quiescent adults allows the transfer of individuals between reproductive and quiescent classes as host and/or weather conditions require. Each stage may have different responses to temperature and other variables.

\section{References}

Andrewartha HG, Birch LC (1954) The distribution and abundance of animals. University of Chicago Press, Chicago

Balachowski M (1950) Sur l'origine de la Mouche de fruits (Ceratitis capitata Wied.). C R Acad Agric Fr 36:259-362

Beaumont LJ, Gallagher RV, Thuiller W, Downey PO, Leishman MR, Hughes L (2009) Different climatic envelopes among invasive populations may lead to underestimations of current and future biological invasions. Divers Distrib 15:409-420

Bieri M, Baumgärtner J, Bianchi G, Delucchi V, von Arx R (1983) Development and fecundity of pea aphid (Acyrthosiphon pisum Harris) as affected by constant temperatures and by pea varieties. Mitt Schwei Ent Ges 56:163-171

Brière JF, Pracros P, Le Roux AY, Pierre SJ (1999) A novel rate model of temperature-dependent development for arthropods. Environ Entomol 28:22-29

Brown JH, Stevens GC, Kaufman DM (1996) The geographic range: size, shape, boundaries and internal structure. Annu Rev Ecol Syst 27:597-623

Carey JR (1991) Establishment of the Mediterranean fruit fly in California. Science 253:1369-1373

Carey JR (1996a) The incipient Mediterranean fruit fly population in California: implications for invasion biology. Ecology 77:1690-1697
Carey JR (1996b) The future of the Mediterranean fruit fly, Ceratitis capitata, invasion of California: a predictive framework. Biol Conserv 78:35-50

Carey JR, Papadopoulos NT, Müller HG, Katsoyannos BI, Kouloussis NA, Wang JL, Wachter K, Yu W, Liedo P (2008) Age structure changes and extraordinary lifespan in wild medfly populations. Aging Cell 7:426-437

CDFA (2003) Preventing biological pollution: the Mediterranean fruit fly exclusion program, www.cdfa.ca.gov/files/ pdf/Medfly_LegisRpt03.pdf

CDFA (2008) California Department of Food and Agriculture 403.1 Plant Quarantine Manual-2008, setting up small boundary for medfly eradication in So. Calif

Christenson LD, Foote RH (1960) Biology of fruit flies. Annu Rev Entomol 5:171-192

Clark JS, Carpenter SR, Barber M, Collins S, Dobson A, Foley JA, Lodge DM, Pascual M, Pielke R Jr, Pizer W, Pringle C, Reid WV, Rose KA, Sala O, Schlesinger WH, Wall DH, Wear D (2001) Ecological forecasts: an emerging imperative. Science 293:657-660

Coetzee J, Hill MP, Schlange D (2009) Potential spread of the invasive plant Hydrilla verticillata in South Africa based on anthropogenic spread and climate suitability. Biol Invasions 11:801-812

Corvetti A, Conti B, Delrio G (1986) Effect of abiotic factors on Ceratitis capitata Diptera Tephritidae: II. Pupal development under constant temperatures. In: Cavalloro R (ed) Fruit flies of economic importance; Joint Ad-Hoc Meeting of the Commission of the European Communities and the International Organization for Biological and Integrated Control, Hamburg, West Germany, Aug 23, 1984. A.A. Balkema, Rotterdam, Netherlands; Boston, USA, pp 141-148

Davis AJ, Jenkinson LS, Lawton JH, Shorrocks B, Wood S (1998) Making mistakes when predicting shifts in species range in response to global warming. Nature 391: 783-786

De Meyer M, Robertson MP, Peterson AT, Mansell MW (2008) Ecological niches and potential geographical distributions of Mediterranean fruit fly (Ceratitis capitata) and Natal fruit fly (Ceratitis rosa). J Biogeogr 35:270-281 
de Wit CT, Goudriaan J (1978) Simulation of ecological processes, 2nd edn. PUDOC Publishers, The Netherlands

Delrio G (1986) Tephritid pests in citriculture. In: Cavalloro R, Di Martino E (eds) Integrated pest control in citrusgroves: proceedings of the experts meeting, Acireale, Italy, 26-29 March 1985. A.A. Balkema, Rotterdam, Netherlands, pp 135-149

Delrio G, Conti B, Corvetti A (1986) Effects of abiotic factors on Ceratitis capitata (Wied.) (Diptera: Tephritidae)-I. Egg development under constant temperatures. In: Cavalloro R (ed) Fruit flies of economic importance. Joint AdHoc Meeting of the Commission of the European Communities and the International Organization for Biological and Integrated Control, Hamburg, West Germany, Aug. 23, 1984. A.A. Balkema, Rotterdam, Netherlands; Boston, USA, pp 133-139

Diamantidis AD, Carey JR, Papadopoulos NT (2008) Lifehistory evolution of an invasive tephritid. J Appl Entomol 132:695-705

DiCola G, Gilioli G, Baumgärtner J (1999) Mathematical models for age-structured population dynamics. In: Huffaker CB, Gutierrez AP (eds) Ecological entomology, 2nd edition edn. John Wiley \& Sons, New York, pp 503-531

Estrada-Peña A (2008) Climate, niche, ticks, and models: what they are and how we should interpret them. Parasitol Res 103(Suppl 1):87-95

Fitzpatrick EA, Nix HA (1968) The climatic factor in Australian grasslands ecology. In: Moore RM (ed) Australian grasslands. Australian National University Press, Canberra, pp 3-26

Fowler G, Garrett L, Neeley A, Margarey R, Borchert D, Spears B (2009) Economic analysis: risk to U.S. apple, grape, orange and pear production from the light brown apple moth, Epiphyas postvittana (Walker). USDAAPHIS- PPQ-CPHST-PERAL, pp 1-28

Gaston KJ (2003) The structure and dynamics of geographical ranges. Oxford University Press, Oxford

GRASS Development Team (2010) Geographic Resources Analysis Support System (GRASS) Software. Open Source Geospatial Foundation Project. http://grass.osgeo.org

Gutierrez AP (1992) The physiological basis of ratio dependent theory. Ecology 73:1552-1563

Gutierrez AP, Baumgärtner JU (1984) Multitrophic level models of predator-prey energetics: II A realistic model of plant-herbivore-parasitoid-predator interactions. Can Entomol 116:933-949

Gutierrez AP, Regev U (2005) The bioeconomics of tritrophic systems: applications to invasive species. Ecol Econ 52:382-396

Gutierrez AP, Nix HA, Havenstein DE, Moore PA (1974) The ecology of Aphis craccivora Koch and subterranean clover stunt virus in south-east Australia. III A regional perspective of the phenology and migration of the cowpea aphid. J Appl Ecol 11:21-35

Gutierrez AP, Mills NJ, Schreiber SJ, Ellis CK (1994) A physiologically based tritrophic perspective on bottom up-top down regulation of populations. Ecology 75: 2227-2242

Gutierrez AP, Pitcairn MJ, Ellis CK, Carruthers N, Ghezelbash R (2005) Evaluating biological control of yellow starthistle (Centaurea solstitialis) in California: a GIS based supply_-demand demographic model. Biol Control 34:115-131

Gutierrez AP, Ellis CK, d'Oultremont T, Ponti L (2006a) Climatic limits of pink bollworm in Arizona and California: effects of climate warming. Acta Oecol 30:353-364

Gutierrez AP, Ponti L, Ellis CK, d'Oultremont T (2006b) Analysis of climate effects on agricultural systems: A report to the Governor of California sponsored by the California Climate Change Center. http://www.climate change.ca.gov/climate_action_team/reports/index.html

Gutierrez AP, Daane KM, Ponti L, Walton VM, Ellis CK (2008a) Prospective evaluation of the biological control of vine mealybug: refuge effects and climate. J Appl Ecol 45:524-536

Gutierrez AP, Ponti L, d'Oultremont T, Ellis CK (2008b) Climate change effects on poikilotherm tritrophic interactions. Climatic Change 87:167-192

Gutierrez AP, Ponti L, Cossu QA (2009) Prospective comparative analysis of global warming effects on olive and olive fly. (Bactrocera oleae (Gmelin)) in Arizona-California and Italy. Climatic Change 95:195-217

Gutierrez AP, Mills NJ, Ponti L (2010) Limits to the potential distribution of light brown apple moth in Arizona-California based on climate suitability and host plant availability. Biol Invasions 12:3319-3331

Hayhoe K, Cayan D, Field C, Frumhoff P, Maurer E, Miller N, Moser S, Schneider S, Cahill K, Cleland E, Dale L, Drapek R, Hanemann RM, Kalkstein L, Lenihan J, Lunch C, Neilson R, Sheridan S, Verville J (2004) Emissions pathways, climate change, and impacts on California. PNAS 101(34):12422-12427

Israely N, Ritte U, Oman SD (2004) Inability of Ceratitis capitata (Diptera: Tephritidae) to Overwinter in the Judean Hills. J Econ Entomol 97(1):33-42

Krainacker DA, Carey JR, Vargas RI (1987) Effect of larval host on life history traits of the Mediterranean fruit fly, Ceratitis capitata. Oecologia 73:583-590

Liedo P, De Leon E, Arrios MIB, Valle-Mora JF, Barra GI (2002) Effect of age on the mating propensity of the Mediterranean fruit fly (Diptera: Tephritidae). Florida Entomol 85:94-101

Lorraine H (1991) The California 1980 medfly eradication program-an analysis of decision-making under nonroutine conditions. Technol Forecast Soc Change 40:1-32

Malacrida AR, Gomulski LM, Bonizzoni M, Bertin S, Gasperi G, Guglielmino CR (2007) Globalization and fruit fly invasion and expansion: the medfly paradigm. Genetica 131:1-9

Meixner MD, Mcpheron BA, Silva JG, Gasparich GE, Sheppard WS (2002) The Mediterranean fruit fly in California: evidence for multiple introductions and persistent populations based on microsatellite and mitochondrial DNA variability. Molecular Ecol 11:891-899

Messenger PS, Flitters NE (1958) Effect of variable temperature environments on egg development of three species of fruit flies. Ann Ent Soc Am 52:191-204

Mita L, Mitasova H (2002) Spatial interpolation. University of Illinois at Urban-Champaign, Urbana, IL

Mitikka V, Heikkinen RK, Luoto M, Araújo MB, Saarinen K, Pöyry J, Fronzek S (2008) Predicting range expansion of 
the map butterfly in Northern Europe using bioclimatic models. Biodivers Conserv 17:623-641

Muñiz M, Gil A (1986) laboratory studies on isolated pairs of Ceratitis capitata-results obtained during the last three years in Spain. In: Cavalloro R (ed), Fruit flies of economic importance; Joint Ad-Hoc Meeting of the Commission of the European Communities and the International Organization for Biological and Integrated Control, Hamburg, West Germany, Aug. 23, 1984. A.A. Balkema, Rotterdam, Netherlands; Boston, MA, USA, pp 125-128

Myers JH, Simberloff D, Kuris AM, Carey JR (2000) Eradication revisited: dealing with exotic species. TREE 15:316-320

Papadopoulos NT, Katsoyannos BI, Carey JR (2002) Demographic parameters of the Mediterranean fruit fly (Diptera: Tephritidae) reared in apples. Ann Entomol Soc Am 95:564-569

Parker IM, Simberloff D, Lonsdale WM, Goodell K, Wonham M, Kareiva PM, Williamson MH, Von Holle B, Moyle PB, Byers JE, Goldwasser L (1999) Impact: toward a framework for understanding the ecological effects of invaders. Biol Invasions 1:3-19

Pemsl D, Gutierrez AP, Waibel H (2007) The economics of biotechnology under ecosystems disruption. Ecol Econ 66:177-183

Phillips SJ, Anderson RP, Schapire RE (2006) Maximum entropy modeling of species geographic distributions. Ecol Model 190:231-259

Pimentel D, Lach L, Zuniga R, Morrison D (2000) Environmental and economic costs of non-indigenous species in the United States. Bioscience 50:53-65

Ponti L, Cossu QA, Gutierrez AP (2009) Climate warming effects on the olive-Bactrocera oleae system on Mediterranean Islands: Sardinia as an example. Global Change Biol 15(12):2874-2884

Powell MR (2003) Modeling the response of the Mediterranean fruit fly (Diptera: Tephritidae) to cold treatment. J Econ Entomol 96:300-310

Rigamonti IE (2004) Contributions to the knowledge of Ceratitis capitata Wied. (Diptera, Tephritidae) in Northern Italy: II Overwintering in Lombardy. Boll Zool agr Bachic Ser II 36(1):101-116
Roura-Pascual N, Brotons L, Townsend Peterson A, Thuiller W (2009) Consensual predictions of potential distributional areas for invasive species: a case study of Argentine ants in the Iberian Peninsula. Biol Invasions 11:10171031

Shoukry A, Hafez M (1979) The biology of the Mediterranean fruit fly Ceratitis capitata. Entomol Exper et Appl 26:33-39

Sivinski J, Holler T, Pereira R, Romero M (2007) The thermal environment of immature Caribbean fruit flies, Anastrepha Suspensa (Diptera: Tephritidae). Florida Entomol 90:347-357

Sutherst RW, Bourne AS (2009) Modelling non-equilibrium distributions of invasive species: a tale of two modelling paradigms. Biol Invasions 11:1231-1237

Sutherst RW, Maywald GF (1985) A computerized system for matching climates in ecology. Agric Ecosyst Environ 13:281-299

Sutherst RW, Maywald GF, Bourne AS (2007) Including species interactions in risk assessments for global change. Global Change Biol 13:1-17

Vansickle J (1977) Attrition in distributed delay models. IEEE Trans Syst Management Cyber 7:635-638

Vargas RI, Walsh WA, Kanehisa D, Jang EB, Armstrong JW (1997) Demography of four Hawaiian fruit flies (Diptera: Tephritidae) reared at five constant temperatures. Ann Ent Soc Am 90:162-168

Vargas RI, Walsh WA, Kanehisa D, Stark JD, Nishida T (2000) Comparative demography of three Hawaiian fruit flies (Diptera: Tephritidae) at alternating temperatures. Ann Entomol Soc Am 93:75-81

Vera MT, Rodriguez R, Segura DF, Cladera JL, Sutherst RW (2002) Potential geographical distribution of the Mediterranean fruit fly, Ceratitis capitata (Diptera: Tephritidae), with emphasis on Argentina and Australia. Environ Entomol 31:1009-1022

Walther GR (2002) Ecological responses to recent climate change. Nature 416:389-395

Wellington WG, Johnson DL, Lactin DJ (1999) Weather and insects. In: Huffaker CB, Gutierrez AP (eds) Ecological entomology, 2nd edn. Wiley, New York, pp 313-353 